\title{
Specify PDGFRA Exons Assessed
}

National Cancer Institute

\section{Source}

National Cancer Institute. Specify PDGFRA Exons Assessed. NCI Thesaurus. Code

C160584.

A request to enter the PDGFRA exons assessed for mutations in this section of the form. 